\title{
BONNEMANN, J. (2016): DAS LEIBLICHE WIDERFAHRNIS DER \\ Wahrnehmung. Eine Phänomenologie des Leib-Seele- VerhältNisses, MünSter: Mentis VerLAG, 407 PP.
}

\author{
Agata Bak \\ UNED (España) \\ agata.bak@gmail.com
}

La presente obra es un ensayo en teoría de la percepción; pero el libro de Bonnemann aspira además a recuperar una dimensión de la percepción que el análisis contemporáneo deja de lado con demasiada facilidad. Su investigación se fragua en un diálogo con pensadores tanto del denominado lado "continental" como "analítico". Dada amplitud y el detalle del estudio, únicamente podemos centrarnos en el desarrollo de su tesis, dejando así al lado muchas valiosísimas interpretaciones y debates.

El estudio se rebela contra una cierta tendencia intelectualizadora en la filosofía de la percepción (p. 18) y aboga por una noción más amplia de este fenómeno, para así dar cuenta también del aspecto "sentido" de la experiencia corporal perceptiva: leibliche Widerfahrnis (elegimos la palabra "experiencia" para traducir Widerfahrnis, aun a riesgo de dejar de lado ciertos aspectos. Widerfahrnis en alemán hace falta a un acontecimiento -doloroso e impactante- que sobreviene. Por otra parte, widerfahren significa experimentar algo, por ejemplo dolores). La teoría estándar de la percepción suele ignorar el hecho 
de que la percepción es también un suceso corporal, y además lo concibe más bien como un hecho perteneciente exclusivamente al ámbito epistemológico (lo sensible es solo un momento del conocimiento sensible), donde el papel del cuerpo es más bien ancilar y anecdótico. Ciertamente hubo un giro en la filosofía de la percepción, gracias a autores como Noë, Heidegger o Sartre. Nada similar ha ocurrido sin embargo con la dimensión pática (pathish) de la experiencia, a pesar de que múltiples autores han hecho referencia a ella en su obra. El presente libro constituye precisamente un esfuerzo por recuperarla e incorporarla como elemento fundamental de la experiencia perceptiva.

En palabras del autor, basta con reflexionar sobre un episodio doloroso o alegre para darse cuenta de que hay muchas maneras en las que las cosas nos afectan; estas experiencias no están bien explicadas en la teoría estándar y epistemológica de la percepción donde predicados como "agradable" o "desagradable" no tienen cabida o están despojados de la referencia al objeto. El objeto que, por su parte, queda reducido siempre al objeto de conocimiento. La crítica de Bonnemann se extiende también a los planteamientos más prácticos y fenomenológicos; de hecho, cree que muchos autores como Schütz o Henry no llegan a plantear adecuadamente el momento pático de la experiencia, y en consecuencia, las cosas que nos atacan, hieren, agradan o asustan. Esto se debe, según el autor, a que falta concebir este tipo de experiencias como una relación original e intencional, esto es, que una cosa puede resultarme directamente agradable o desagradable, sin un andamiaje conceptual en el que sostener lo pático.

El libro pretende, pues, dar cuenta de lo pático en tanto que perceptual e intencional.

Dentro de este programa el autor intenta mantenerse en todo momento en el difícil equilibrio de estudiar lo pático en el marco perceptual. Quiere, así, evitar tanto el extremo que disuelve la percepción y lo pático en una fenomenología del cuerpo y como aquel en el que la percepción se vuelve "transparente" en la epistemología. La percepción se torna una relación originaria, en la que emerge tanto el sujeto como el objeto. Parece ser el único camino para superar el dualismo instaurado en el corazón de la teoría de la percepción.

La primera parte del libro está consagrada al problema de la teoría estándar de la percepción, y los interlocutores del autor varían desde Aristóteles y Kant, hasta Plessner, Jonas y Strauss. El rasgo más prominente en el que se 
centra Bonnemann es el dualismo entre percepción, comprendida como parte del conocimiento sensible (y por ende un término epistemológico), y la experiencia (Widerfahrnis), concebida tradicionalmente como un sentimiento que no se corresponde con ningún objeto o cualidad objetiva en el mundo (es weltlos). A juicio del autor, incluso Jonas, cuya crítica de la noción tradicional de la percepción se estudia en el capítulo segundo, recae en última instancia en esta polaridad, puesto que concibe la afección corporal como algo que en última instancia carece de conexión con el mundo, y de que tenemos que abstraer para producir conocimiento. Strauss, por su parte, concibe las sensaciones, las Empfindungen, como uno de los estados que se refieren al mundo, pero igualmente describe la experiencia pática como auto-afección no intencional. Bonnemann cree que, por el contrario, este dualismo ha de ser superado, puesto que la misma percepción da cuenta también de los intereses vitales y de las necesidades del sujeto. El sufrimiento también abre ciertas propiedades del objeto (p. 56), propiedades que desde luego no son alcanzables para un sujeto distanciado en una actitud puramente epistemológica.

El siguiente paso consiste en analizar detalladamente distintas teorías de la percepción (capítulo 3) para mostrar tres maneras de obviar la dimensión pática. La primera de ellas consiste en considerar la percepción como parte del conocimiento sensible, cuestión ya analizada y representada aquí por Searle. Seguidamente, se analizan dos aproximaciones que niegan la primacía teórica de la percepción. Una de ellas concibe la percepción en términos prácticos (así Dewey y Heidegger), mientras que la segunda reduce la percepción misma a una filosofía del cuerpo (Henry).

Pues bien, las tres posturas adolecen del mismo problema y es que no dan cuenta de la compleja relación establecida en la percepción. A la filosofía de Searle le falta la intuición del cuerpo y que el sujeto es algo más que el sujeto del conocimiento. Las teorías de la acción aciertan al escribir otras relaciones posibles con el objeto (por ejemplo, la Zuhandenheit); no obstante, una relación circular entre acción y percepción acaba por marginar el cuerpo, y finalmente concibe la experiencia pática en términos demasiado intelectualistas. Según Bonnemann lee a Schütz, "el sabor del chocolate tiene para Schütz una relevancia exclusivamente motivacional, en tanto que he aprendido que el chocolate me sabe bien" (p. 115). 
Es un compromiso de índole muy teórica y no explica cómo las propiedades del objeto se puedan dar directamente. En el otro extremo, Henry afirma claramente que la experiencia de tipo pático acontece en la intimidad de la subjetividad y no como efecto de mundo sobre un sujeto encarnado (p. 119). El último capítulo de esta parte examina las nociones contemporáneas de la encarnación (embodiment), el enactivismo y corrientes "postcognitivistas", que tampoco consiguen dar cabida del concepto que busca Bonnemann. No obstante, Bonnemann sí que encuentra allí a un aliado para su empresa: es Schaun Gallagher.

La segunda parte del libro se centra en el análisis del fenómeno pático en tanto que percepción y relacionado con el mundo. El eje que articula este estudio son dos conceptos tomados en el sentido que les da Gallagher: Körperschema y Körperbild. Y aunque Bonnemann subraya que la concepción de Gallagher tiende a concebir la experiencia pática exclusivamente en términos de dolor/placer, solo a nivel reflexivo de la experiencia y únicamente en referencia al cuerpo, y por ende no consigue determinar el carácter intencional de la dimensión pática, la distinción que maneja el autor anglosajón le parece de extrema utilidad. Körperschema hace referencia a los procesos inconscientes e irreflexivos en cuyo flujo está involucrado el sujeto. Es el nivel prerreflexivo de la percepción, en el que lo pático está orientado hacia el mundo y tiene por tanto un momento de intencionalidad. Los objetos se donan como placenteros, amenazantes, demasiado fríos, etc. Es solo en un nivel más alto, en el momento de Körperbild ("sistema de percepciones, actitudes y creencias pertenecientes al cuerpo propio", dirá Bonnemann en p. 147), donde el dolor u otra experiencia de este tipo se convierte en una sensación localizada y se refiere más bien al sujeto y no al mundo. El autor defiende, pues, que esta experiencia no es en primer lugar un estado interno del cuerpo, sino que concierne también a las cualidades objetivas del mundo perceptivo (p. 173).

En la segunda parte se estudia la dimensión prerreflexiva y dirigida hacia el mundo de la experiencia pática. Se trata de concebirla, no como fenómeno del Leib, sino como el fenómeno de la cosa mediado por el cuerpo (p. 323). El autor subraya de manera reiterada que es menester distinguir entre la dimensión práxica y la pática, interrelacionadas pero no reducibles, como se puede leer en sus análisis de la obra de Sartre. Y es que mientras es bastante común conceder que el compromiso (acción) es necesario para el conocimiento, el compo- 
nente afectivo no ha tenido la misma suerte. Lo que subraya Bonneman es que el mundo no solo sirve para mis propósitos, no solo me invita a actuar, sino también me hiere y me destruye (p.169), poniendo así de relieve nuestra vulnerabilidad radical. Esta dimensión no es probablemente tanto la resistencia de las cosas (Widerstand), cuanto su capacidad de afectarme (widerfahren). Pero de alguna manera chocante (chocante en el sentido literal también), estas experiencias nos anclan en el mundo, descubriendo nuestra materialidad. No es tanto la constitución de sentido, cuanto un acontecimiento (Ereignis).

Seguidamente el autor analiza el tipo de intencionalidad presupuesto en esta relación mundo-sujeto, descubriendo que su objeto es un valor, cuya primera expresión podría ser "demasiado" o "demasiado poco", ciertos máximos y mínimos. Su carácter normativo no debe de concebirse in abstracto, como un ideal, ni comparado con normas sociales. Su única referencia es el exceso o la carencia que afecta al cuerpo.

Por supuesto, esta clase de objetos o propiedades están en relación constante con lo práctico y teórico y se influyen mutuamente. Su carácter objetual se confirma además por el hecho de que la experiencia en la que se dan también abre un horizonte, "horizontes amenazantes de la percepción", como bellamente se describe en la páginas 225 y siguientes.

Probablemente el filósofo que le resulta más idóneo a Bonnemann es Levinas y su concepción de la alegría, junto a la de "la vida que vive de" (vivre de). En ella tienen cabida muchos de los elementos que Bonnemann emplea para describir su idea de la dimensión prerreflexiva de la experiencia pática: el carácter intencional de lo pático, el hecho de que tiene un objeto (elemento, en palabras del filósofo francés), su carácter irreductible (y para Levinas primario) y positivo. El capítulo dedicado a este filósofo nos resulta de sumo interés para saber cómo describir de manera adecuada esta experiencia. Levinas habla del "baño" en el "medio" (p. 258 y ss) donde todavía no hay mundo, ni objetos, ni cosas, solo afecciones como el tacto suave de la brisa (pero antes de ser tematizada), como el sol sobre la piel. Estas experiencias límite son más bien el punto de arranque de la experiencia pática, puesto que el tránsito hacia lo práctico o teórico ("desde lo que afecta" a "la cosa afectante") es más bien rápido.

La experiencia pática, y esta es la tesis de la última parte del estudio, nos enseña que nuestro cuerpo vivido (Leib) está implicado mundanamente y que hecha sus raíces en lo que no es (p. 277). La tercera parte pretende, pues, dar 
cuenta de la experiencia del cuerpo en la experiencia pática, que se corresponde con el nivel reflexivo o de Körperbild. El último capítulo quiere indagar en lo que eso significa para la teoría del sujeto.

La noción central presentada en esta ocasión es als-Körper-von-der-WeltGehabtwerden, encontrada en el pensamiento de Plügge. Esta expresión incide en el hecho subrayado por algunos fenomenológos como Böhme, a saber, que el Körper es igualmente parte de nuestra experiencia del mundo, como límite del Leib, y más, que da cuenta de nuestra experiencia como cosa entre cosas (p. 296).

Estar poseído por el cuerpo también juega con la observación de Marcel de que no somos capaces de poseer totalmente nuestro propio cuerpo. Sería, pues, justo esta estructura la más idónea para expresar la relación entre Leib y mundo, en la que el segundo le acaece, le afecta al primero (p. 301).

Esta estructura comprende tres elementos claves: "ser cuerpo vivido" (Leib), el momento de la experiencia. "Tener un cuerpo" (Körper), esto es, tener algo con el que explorar el mundo, puesto que son de la misma índole, y "ser tomado por el propio cuerpo" (Mein Körper hat mich), que apunta al hecho de que las cosas puedan afectarme (iO atacar!, se dice en la p. 302).

En este sentido Bonnemann va más allá de Jonas, Böhme, Schmitz y otros, en tanto que no solo aboga por una consideración más amplia de lo pático, sino que también lo inserta en el marco intencional, parte de la relación cuerpomundo de carácter apertural. Mientras que los autores antes mencionados tienden a contentarse con un cierto carácter weltlos, sin mundo, del Leib y la afección, centrándose preferiblemente en "marcas" antes que incluirlas en un arco intencional del mundo que las "causa". Leib tiende a concebirse como un todo más o menos cerrado que porta ciertas marcas. $Y$ aunque sí que llegan a conceptualizar el dinamismo de Leib y Körper, parecen no dar este último paso. Sí parece que lo da Plessner en sus análisis de la risa y el llanto; y es que el autor alemán introduce, influido posiblemente por Plügge, una dimensión intermedia, también subdividida entre conciencia de ser Körper, ergo afectado por el mundo, y conciencia de ser una cosa corporal. Desde esta óptica analiza el llanto y la risa como manifestación del cuerpo sufriente; y sufriente significa aquí desorganización, súbita posesión por parte del cuerpo, y consecuente pérdida de posición gobernante. Esta dimensión es precisamente la que nos permite concebir lo pático no solo como "marca", sino como relación con el mundo. 
Körperbild no es sino la conciencia experiencial de ser un Körper, experimentada desde nuestro Leib. Tenemos que concebir Widerfahrnis como una experiencia fenoménica, en la que aparece tanto mi cuerpo vivido como mi cuerpo material (p. 325), concebir causalidad y motivación como entretejidas. De otra manera nuestra experiencia sería en última instancia sin mundo.

Bonnemann evita caer en la tentación de concebir Körper como algo meramente biológico y, por tanto, no fenoménico. Tampoco está de acuerdo con Böhme quien explora la posibilidad de que la corporalidad (Körperlichkeit) y el yo no ssean sino abstracción de Leib, lo único propiamente dado en la afección. Debería resultar patente que Bonnemann optará por considerar Leib y Körper como co-originarios. El argumento que esgrime a favor de ello se encuentra en el famoso ejemplo husserliano de las dos manos tocándose que son a la vez tanto el descubrimiento del Leib como el del Körper. Solo desde esta perspectiva es comprensible cómo von-Körper-Gehabtwerden, la experiencia pática de mi propia realidad, puede ser anterior a cualquier acción, de la misma manera a como las Empfindnisse o sensaciones localizadas son anteriores a lo cinestésico. Es el "ser irritado por el mundo" (p. e. en p. 337) lo que constituye propiamente los campos sensoriales del cuerpo vivido. El momento reflejo, la aprehensión del Körperbild, consiste en un cambio de atención, paralelo al cambio de atención desde el objeto, hacia el sujeto con su textura particular. Hasta que no lo hagamos, nuestro Leib permanece invisible, no tematizado. Esto significa a su vez que tanto Körper-haben como Leib-sein son instancias reflexivas posteriores a la primera experiencia de estar con el mundo.

El estudio culmina con la descripción de la noción de chair, la cual parece englobar los aspectos destacados en el estudio: cierta dualidad o más bien reversibilidad del cuerpo, y su carácter intrincado en el mundo, de tal manera que a veces las dos nociones llegan a confundirse. El dualismo parece superarse en tanto que ni el sujeto lo es totalmente, ni las cosas son totalmente ajenas. Körper y Leib, concluye el autor, están entretejidos, ya que la experiencia del Segundo implica ya la dación del primero. (pp. 358ss). La noción del yo que emerge de esta posición no es tanto o solo la de un sujeto sufriente, sino más bien un sujeto anclado en el mundo, y cuyo ser no es "ni conocimiento, ni praxis, sino alegría" (p. 363). 